Presented at the $13^{\text {th }}$ Global Brand Conference, 2nd - 4th May 2018, Northumbria University, Newcastle, UK

\title{
Exploring Nostalgic Advertising Effects on Social Media: A Case of UK Retail Bank Brand.
}

\author{
Emmanuel Mogaji \\ University of Greenwich \\ e.o.mogaji@greenwich.ac.uk
}

Keywords: Nostalgic Advertising, Social Media, Facebook, Bank brand, Halifax

\section{Purpose}

Halifax is a British bank founded 1852, merged with Bank of Scotland to form HBOS in 2001 and was acquired by Lloyds TSB in 2009. Shifting away from their usual advertisements using Staff member as choirs, Halifax has been adopting cartoon characters from classic shows for their advertisements since April 2016. They have used characters from four different shows Top Cat, The Flintstones, Scooby-Doo and lately the Thunderbirds.

While practitioners have adopted nostalgia-based marketing and advertising strategies, consumers' responses have also been empirically considered, Pascal, Sprott, \& Muehling (2002) conceptualised nostalgia as an idealised view of the past which they believed evoked consumers emotions, and more likely to be a positive emotion. They developed the Nostalgia scale (NOST) to empirically establish a relationship between the positive attitude evoked after exposure to a nostalgic advert and a positive attitude towards the brand and an increased likelihood of purchase, other studies have also come to this agreement that nostalgic feelings generated by an advertisement may produce correspondingly more favourable evaluations of the advertised brand (Bambauer-Sachse \& Gierl, 2009; Zhao, et al., 2014).

Given the popularity of this advertising technique and how it may positively enhance advertising outcomes (Pascal, et al., 2002), the theoretical argument of this paper is how the brand context affects these outcomes. No doubt, nostalgia can evoke positive emotions, but can that be same for a retail bank, taking into consideration the utilitarian nature of financial service and unprecedented turbulence, uncertainty and lack of trust in the sector. McCracken (1989) developed the meaning transfer model which suggests that like celebrities, these 
cartoon characters can also transfer their embedded meanings to the consumers, especially within service marketing where tangibilizing the intangible can be achieved by using verbal and visual cues to communicate quality service. This place a lot of importance on the visuals used in service advertisements and further highlighting the possibilities of different meanings transferred from the visual elements of advertisements to the brand.

Based on the pre-existing knowledge about these characters and the banking industry, this study aims to explore the emotional reaction towards the nostalgia advertisements and the Halifax brand within the digital sphere; as social media is transforming how consumers interact with brands and how brand-related content is consumed, this research analysed user-generated contents in the form of comments on the advertisements; as previous studies have either used fictitious advertisement or scale measurement, these comments are considered a unique data set.

In the study, the following questions are addressed in line with this aim:

RQ1: What are the attitudes towards these advertisements?

RQ2: Has the advertisements encouraged a positive attitude towards the bank brand RQ3: Has the positive attitude (if any) indicates an intention to switch or patronise the bank?

\section{Methodology}

The research methodology used for this study is content analysis. Following on studies by Mogaji et al. (2016), comments from all the four advisements on the Bank's verified Facebook page were extracted using NCapture on NVivo; the data collection process involved viewing the comments (including clicking on "see more") and replies on all the advisements. Also, comment data-screening processes were put in place to inspect the extracted comments, identifying outliers and dealing with incongruent comments. Profane comments, comments that were not in English or those not relevant to the advertisements or the brands (for example, when people were just mentioning a friend to get their attention) were removed before coding.

In line with the widely employed typology (Eid \& Diener, 2001; Laros \& Steenkamp, 2005); emotions reported in the comments towards the advertisement and the brand were coded deductively as four positives (affection, contentment, happiness and pride) and four negatives (anger, fear, sadness and shame). To guarantee the objectivity and reliability of the results, two individuals, independent of each other, served as the coders. They coded all the comments for this study; their intercoder reliability was assessed using both Cohen's kappa and Krippendorff's alpha level of agreement, which ranged from 0.996 to 1.00.

Participants (customers/Facebook users) were not part of any interview or laboratory setting to elicit their attitudes. They were not asked any questions about their relationship with the 
banks, and there were no concerns about confidentiality and anonymity because, unlike interviews, their comments were publicly displayed online. All indicators of their attitudes towards the bank brands were derived from subsequent analysis of their online comments to the brand's advertisements. Lane and Menzies (2015) argued that this research approach could be a method of determining customers' attitudes towards brands from observation only.

\section{Findings}

The research found that customers were able to freely express their opinions and thoughts about bank brands on social media. This finding is consistent with the findings of Mogaji (2016), who explored the emotional responses to advertisements on social media.

There were positive attitudes towards all the four advertisements; there were verbal reports of excitement, happiness and nostalgic feeling as consumers shares their fond memories of the cartoon characters. However, there was no indication of a favourable perception of the advertised brand or a likelihood intention to purchase. There was more negative attitudes towards the brand (Halifax) with no intention to switch or open an account, as some questions why the bank was using the characters, it appeared consumer cannot see the congruency between their favourite cartoon brand and a bank.

In addition to the fact that they cannot associate the characters with the brands, there were concerns regarding how the storyline and the characters as it aligns with Halifax' brand values. The Top Cat seems to get the most attention, albeit being the first one but perhaps the story that was being associated with the advert. The advertisement featuring Top Cat advertisement was for mortgage and often people questions how the bank can give a loan to such a character in real life.

With the negativity surrounding the cartoon characters and their storylines, there was no much indication of interest or intention to switch the banks based on the advertisements; it must be acknowledged however that some individuals who have received quality services in their local brand can publicly say well of the brands.

\section{Theoretical Implications}

These findings provide further understanding about the relationship between positive emotions evoked by nostalgic advertisement and attitude towards the brand, and the advertisement, the congruency between the nostalgic element and the brand is very important, further highlighting the importance of embedded meaning transfer within advertisements. The Meaning Transfer Theory has been previously explored with celebrities as their associated meaning can be transferred to the brand they are endorsing, and in this case, the study also 
shows that cartoon characters as well do have their embedded meanings which may not always align with the brand as seen with Top Cat.

Results support previous findings that advertisements eliciting nostalgic reactions can positively influence consumers' attitude toward the advertisement (Pascal, et al., 2002). However, there was a negative attitude towards the brand which questions the previous theory that positive ad feelings evoked with nostalgia advertisement $\rightarrow+A_{a d} \rightarrow+A_{b} \rightarrow+L_{p i}$. Also, the congruency between emotionally appealing nostalgic advertisement and financial services creates an opportunity for further research, and as Bambauer-Sachse \& Gierl (2009) concludes that nostalgic advertising is appropriate for advertising products that are likely to be subject to mental images, perhaps nostalgic advertisement may not be suitable for financial services.

\section{Practical Implications}

Using old cartoon characters seems to be well received regarding the nostalgia feeling, consumers find it emotionally appealing however there are two practical implications to consider. Firstly, the congruency between the brand (a bank) using such animation as they appear to be friendly and bring back memories and secondly, the attached meanings and preexisting knowledge about the cartoon characters unlike other animated characters specifically designed for brands such as the Lloyds TSB and the TSB Bank. For example, the Top cat is seen as an unmarried, homeless, unemployed fly guy with many unrelated kids from a dodgy area who had already been moved on by the Police and got a mortgage from Halifax; this may suggest that anyone can get a mortgage from the bank which is not true.

\section{Originality/Value}

By analysing user-generated contents on social media, a unique data set, this study offers an original idea; providing insight into nostalgic advertisement and the conversations surrounding them in the digital sphere. These expositions give insight into what consumers can relate with and how best to develop other creative strategies. Also, this study further contributes to the growing body of literature highlighting the relationship between positive emotions aroused through nostalgia and a positive attitude towards the advertisement and brand.

\section{References}

Bambauer-Sachse, S. \& Gierl, H., 2009. Effects of Nostalgic Advertising Through Emotions and the Intensity of the Evoked Mental Images. In: A. L. McGill \& S. Shavitt, eds. Advances in Consumer Research Volume 36, eds.. Duluth(MN): Association for Consumer Research, pp. 391-398. 
Eid, M. \& Diener, E., 2001. Norms for experiencing emotions in different cultures: Inter- and intranational differences. Journal of Personality and Social Psychology, 81(5), pp. 869-885.

Lane, M. \& Menzies, V., 2015. An analysis of user engagement in student facebook groups. Student Success, 6(2), pp. 93-98.

Laros, F. J. \& Steenkamp, J. B., 2005. Emotions in consumer behavior: A hierarchical approach. Journal of Business Research, 58(10), p. 1437-1445.

McCracken, G., 1989. Who is the celebrity endorser? Cultural foundations of the endorsement process. Journal of Consumer Research, 16(3), pp. 310-321.

Mogaji, E., 2016. This advert makes me cry: Disclosure of emotional response to advertisement on Facebook. Cogent Business \& Management, 3(1), p. 1177906.

Mogaji, E., Farinloye, T. \& Aririguzoh, S., 2016. Factors shaping attitudes towards UK bank brands: An exploratory analysis of social media data. Cogent Business \& Management, 3(1), p. 1223389.

Pascal, V. J., Sprott, D. E. \& Muehling, D. D., 2002. The Influence of Evoked Nostalgia on Consumers'Responses to Advertising: An Exploratory Study. Journal of Current Issues \& Research in Advertising, 24(1), pp. 39-47.

Zhao, G., Muehling, D. D. \& Kareklas, I., 2014. Remembering the good old days: The moderating role of consumer affective state on the effectiveness of nostalgic advertising. Journal of Advertising, 43(3), pp. 244-255. 